\title{
Desafios de pesquisa em Jornalismo Cultural: estratégias metodológicas para compreender os processos editoriais no campo cultural*
}

\section{RESUMO}

Como pensar em dispositivos metodológicos para facilitar o ensino e a formação em Jornalismo Cultural, considerando as especificidades do setor, o processo de produção editorial e, pois, a compreensão e análise de ações e estratégias na área? O texto sugere perspectivas para estudos que têm como objeto produtos, serviços ou processos de produção em Jornalismo Cultural, de modo a contribuir para a busca de referenciais teóricos e para o aprimoramento da formação profissional na área.

\section{PALAVRAS-CHAVE}

\section{Jornalismo Cultural}

Métodos de Pesquisa em Jornalismo

Produção Jornalística da Cultura

\section{ABSTRACT}

How to think about methodological mechanisms to become easy the teaching and formation on cultural journalism, considering specification of field, the process of editorial production and, thus, understanding and analysis of action and strategies on field? The article suggests perspectives to studies that have as subject products, services or process of production on Cultural Journalism, which can contribuite to find out theoretical references and improvement of formation on the field.

\section{KEY-WORDS}

Cultural Journalism

Methods of Journalism Research

Journalistic Production of Culture

\author{
Sérgio Luiz Gadini \\ Professor do Curso de Comunicação Social/ Jornalismo da UEPG/PR/BR \\ sergiogadini@yahoo.com.br
}

0 presente texto surgiu de uma constatação no setor de Jornalismo Cultural no Brasil: a (quase completa) inexistência de referências metodológicas para compreender e analisar processos, estratégias e produtos jornalísticos desenvolvidos para e no campo cultural. Habitualmente, discute-se bem mais cultura e o jornalismo de um modo geral e bem menos as especificidades que tendem a caracterizar o Jornalismo Cultural (JC). Esta ausência de dispositivos metodológicos marca não apenas os cursos de graduação em Jornalismo, mas se revela também nas pesquisas e estudos publicados ao longo dos últimos anos no País.

Assim, o texto que segue faz uma breve apresentação temática e conceitual, indicando, em seguida, pistas que pode(ria)m operar como mecanismos metodológicos para investigações da área. Em certa medida, o texto também pontua algumas reflexões sobre o JC que podem auxiliar na compreensão e na própria atividade pedagógica nos cursos de Jornalismo. É claro que não se trata de apresentar nenhuma receita ou fórmula para resolver os inúmeros dilemas metodológicos do Jornalismo. Antes, busca-se atender ao desafio de levantar referenciais teórico-metodológicos próprios ao estudo do Jornalismo Cultural e, conseqüentemente, buscar uma formação profissional mais sólida na área, em sintonia com algumas das inúmeras transformações do setor, registradas a partir das últimas décadas do século XX. ${ }^{1}$

\section{Contextualização temática e conceitual sobre o estudo do jornalismo cultural}

A discussão sobre jornalismo cultural no Brasil, muitas vezes, se confunde - quando não se restringe com estratégias de divulgação de determinados atores e produções, numa atuação bastante próxima do marketing e da publicidade. Daí porque é importante delimitar o que se entende por jornalismo cultural e, pois, refletir sobre o quê e como se faz jornalismo cultural, em torno dos mais diversos suportes midiáticos, dialogando com os estudos e investigações da área, a partir das estratégias metodológicas. 
Em certo sentido, pode-se dizer que o jornalismo cultural, como toda 'invenção' discursiva, oscila entre a reprodução do já existente e disponível para o consumo e a criação parcialmente permitida e existente nessas editorias. Uma criação que se dá por meio de critérios de noticiabilidade, que orientam a escolha de pautas, matérias, ensaios, críticas, notas breves e imagens que reforçam ou imprimem visibilidade a certas situações nem sempre conhecidas do público. São situações plurais que acionam a perspectiva do jornal como um "campo polêmico" (Mouillaud, 1997) que envolve e também legitima o produto (meio e espaço) jornal.

A professora María J. Villa (2000) diz que o jornalismo cultural apresenta-se como um "discurso periodístico complejo que se articula no sólo con prácticas, saberes y convenciones históricamente determinadas, sino con cánones estéticos situados en el mismo contexto".

Iván Tubau (1982, p. 35), autor de uma das mais conhecidas publicações sobre o assunto, (Teoria y pratica del periodismo cultural), lançada no início da década de 1980, define o jornalismo cultural como a "forma de conocer y difundir los productos culturales de una sociedad a través de los medios masivos de comunicación".

Por sua vez, o argentino Jorge Rivera (1995, p. 19) faz a seguinte observação em torno da complexidade e abrangência do conceito:

Se ha consagrado historicamente con el nombre de periodismo cultural a una zona muy compleja y heterogénea de medios, géneros y productos que abordan con propósitos creativos, críticos, reproductivos o divulgatorios los terrenos de las 'bellas artes', 'las bellas letras, las corrientes del pensamiento, las ciencias sociales y humanas, la llamada cultura popular y muchos otros aspectos que tienen que ver con la producción, circulación y consumo de bienes simbólicos, sin importar su origen o destinación estamental.

As referências acima, mesmo que rapidamente, indicam o grau de pluralidade, abrangência ou mesmo variedade de produtos, serviços, suportes que confluem para essa "zona heterogênea" da produção editorial da cultura contemporânea... em formatos jornalísticos, seja na forma de informação, serviço, crítica, dentre outras variações de abordagem discursiva.

A problematização do campo envolve, ainda, outros aspectos, como os (complicados) critérios de noticiabilidade. Marcelo Coelho (2003) discute a referência editorial no jornalismo cultural brasileiro:

$\mathrm{O}$ aspecto mais problemático do jornalismo cultural me parece ser a notícia, a reportagem, a entre- vista; e a falha que mais me chama a atenção nos cadernos culturais, nas revistas, é a precariedade com que se discutem os critérios pelos quais se decide noticiar ou não determinado assunto. Pois, se excetuarmos os casos mais óbvios - a morte de Jorge Amado, os cem anos de Drummond, a premiação do Nobel ou o Oscar -, não há muito critério para estabelecer o que noticiar ou não numa primeira página de um caderno cultural. Ou melhor, há critérios demais. Não se está pensando especificamente no que é jornalístico ou no que é importante 'em si'- uma eleição presidencial, um bombardeio -, pois a notícia, mais do que nunca, está impregnada de valor, havendo possibilidades de escolha muito amplas para a pauta de cada dia num caderno cultural (Coelho, 2003, p. 134).

\section{0 presente texto surgiu de} uma constatação no setor de Jornalismo Cultural no Brasil: a (quase completa) inexistência de referências metodológicas para compreender e analisar processos, estratégias e produtos jornalísticos desenvolvidos para e no campo cultural.

Compreende-se, então, por Jornalismo Cultural ${ }^{2}$ os mais diversos produtos e discursos midiáticos orientados pelas características tradicionais do jornalismo - atualidade, universalidade, interesse, proximidade, difusão, clareza, dinâmica, singularidade e pluralidade, dentre outras - que, ao abordar assuntos ligados ao campo cultural, instituem, refletem e projetam modos de ser, pensar e viver dos receptores, efetuando assim uma forma de produção singular do conhecimento humano (Genro Filho, 1998) no meio social onde o mesmo é produzido, circula e é consumido.

Participam, assim, desse cenário uma ampla variedade de atores sociais: repórteres que executam suas 
pautas, a partir das orientações editoriais; colaboradores que escolhem os assuntos a ser abordados; fontes noticiosas que diariamente enviam material de assessoria às redações para publicação; editores que seguem rotinas de uma tradição forjada pelas indústrias da arte e cultura; leitores que enviam cartas criticando enfoques jornalísticos ou apresentando sugestões de pautas; artistas e profissionais independentes que constantemente reclamam mais atenção aos assuntos regionais, alegando não ter espaço para divulgar seus trabalhos; além de outros atores que recebem e se identificam com a cobertura e agendamento apresentado pelos referidos periódicos.

E como isso se articula com a perspectiva metodológica? Toda investigação constitui-se num campo epistêmico, resultante de uma interação dinâmica entre as bases teórico-conceituais, ou paradigmas, e as técnicas ou procedimentos de investigação que são, por sua vez, orientados por essas mesmas bases.

Desta forma, toda pesquisa (ou, ao menos, boa parte dos estudos que reivindicam uma referência lógica e conceitual), como processo, vai delineando os rumos da investigação: discussões, leituras, observações empíricas e análises apresentadas pelos atores sociais que configuram os diferentes ângulos do problema proposto possibilitam tirar o estudo de um plano pretensamente teórico, como também não conceber a investigação como uma busca meramente empírica, centrada unicamente nos objetos de análise. Assim entendido, "o campo de pesquisa é definido essencialmente por uma dinâmica que resulta de uma rede de articulações verticais e horizontais tecida pelo raciocínio científico" (Lopes, 1997, p. 82).

Em outros termos, não há como pensar em qualquer referência metodológica sem trabalhar, simultaneamente, com orientações conceituais (implícitas ou explícitas) que cercam o problema formulado e, ao mesmo tempo, o objeto escolhido para estudo, análise ou proposição.

E como isso acontece quando se tem um objeto de pesquisa na área de jornalismo? Habitualmente, dizse que o jornalismo é forjado por "olhares interdisciplinares", demanda esforço multifocal, panorâmicas e interesses diversos que deveriam considerar o denominado "campo de passagem" ou "encruzilhada comunicacional" da sociedade contemporânea. Isso tudo procede e, em certos aspectos, é mesmo defensável. Mas, seguramente, não é suficiente para situar, cercar e melhor explicar as especificidades que tipificam o jornalismo e, neste caso em pauta, as peculiaridades que caracterizam o jornalismo cultural contemporâneo.
Vejamos alguns aspectos que podem operar como dispositivos metodológicos, dialogando com objetos e problemas de pesquisa em jornalismo cultural. É claro que muitas das várias técnicas, mesmo que eventualmente possam remeter às polêmicas em torno de paradigmas clássicos da sociologia, podem ser consideradas como complementares ${ }^{3}$ na busca das informações necessárias à pesquisa. Neste sentido, levantamentos, técnicas de coleta de dados, entrevistas, entre outros procedimentos, podem contribuir para uma maior compreensão das lógicas que orientam o campo cultural.

Primeiramente, não há como desconsiderar os interesses e estratégias das indústrias culturais, e de empresas de outros ramos de produção que investem em cultura no Brasil e no mundo. Esses indicadores sobre os principais "investidores" na área não podem ser obtidos sem ter presente grupos empresariais que também investem em atividades, iniciativas ou eventos culturais, seja pelo aval ou não de leis de incentivo à cultura (que asseguram dedução fiscal). Oportuno lembrar que nem todas as corporações que investem e apóiam ações e iniciativas da área integram diretamente o campo de produção cultural.

Pode-se dizer que, nesse sentido, qualquer estudo sobre jornalismo cultural demanda a caracterização de algumas das variáveis da indústria cultural na instituição do campo cultural brasileiro, seja no que diz respeito ao cinema, à música ou à produção televisiva, publicitária, áudio-imagética e textual, dentre outras. Aliás, a referência à indústria da cultura integra essas inúmeras formas de produção simbólica, envolvendo o processo de elaboração, circulação e recepção (adesão, indiferença ou rejeição).

Em relação às ações e táticas de agendamento, não há como ignorar, também, alguns mecanismos que as assessorias lançam mão para obter espaço nas editorias, programas e periódicos de cultura - seja pelo envio de release, produto promocional, convites, campanhas sistemáticas ou eventuais peças publicitárias.

Dependendo dos objetivos da pesquisa, é igualmente oportuno levar em conta o ângulo de envolvimento dos profissionais que trabalham no campo cultural agentes, produtores, críticos, atores, músicos, cineastas, escritores - uma vez que tais atores também participam, direta ou indiretamente, da instituição cotidiana do campo cultural pelas respectivas ações, projetos ou estratégias de intervenção social.

Tal expectativa justifica-se - como aspecto importante nas pesquisas da área - pelo próprio interesse no agendamento, como forma de visibilidade e legitimação, de seus projetos e interesses no espaço social. A 
ilustração é simples: em cada cidade média, onde exista estrutura de consumo e público para um jornal com caderno cultural diário, os produtores, críticos e intelectuais geralmente integram um grupo (muitas vezes, seleto) de colaboradores, críticos ou interlocutores que dialogam com os repórteres e editores de cultura. E buscam, assim, não só o reconhecimento público de suas atividades como procuram tornar visíveis seus modos de pensar e explicar a sociedade.

Guardadas as proporções, mesmo que os jornais tenham se tornado bem mais "integrados" a sistemas pré-estabelecidos por circuitos informativos, por vezes agenciados e associados a outros meios e empresas, essa situação não é novidade no cenário cultural brasileiro. A grande diferença, talvez, resida numa gradativa redução dos espaços outrora dedicados ao campo intelectual - vide os suplementos culturais da década de 1950, em especial nos jornais do Rio de Janeiro -, resultante, dentre outros, da associação de movimentos culturais a grupos políticos, especialmente durante a ditadura militar; do fortalecimento da "cultura" televisiva no cotidiano brasileiro; do desmonte da vida social de uma reduzida classe média nas principais cidades do País e, finalmente, de uma simultânea ampliação dos mercados segmentados.

Essa série de fatores que integra o campo cultural da contemporaneidade está, portanto, associada à expectativa que profissionais e agentes culturais construíram com base em relações políticas, econômicas e culturais que marcaram o passado recente da história do Brasil. Obviamente, vários produtores e agentes culturais não vivenciaram as transformações culturais experimentadas entre os anos 1950 e $2000^{4}$. Mas, com certeza, foram influenciados - na universidade, nos grupos de teatro, cineclubes, movimentos literários, musicais ou políticos - por uma trajetória que marcou bem mais que uma geração de intelectuais na história brasileira. É nesse contexto que compreender o olhar dos produtores e agentes culturais que interagem nos processos de produção editorial pode auxiliar em estudos da área.

Variações de formatos discursivos, influências mútuas, tendências e hábitos também são forjados nas interações culturais operadas pelo jornalismo, pela publicidade, pelo cinema, dentre outros setores. Tais conexões podem ser melhor compreendidas pela caracterização histórica de aspectos que indicaram transformações sociais no campo midiático. Para entender o jornalismo cultural dos diários impressos brasileiros do século XXI, por exemplo, é fundamental entender como eles foram criados e, gradualmente, forjaram mudanças editoriais, técnicas e temáticas, chegando aos atuais formatos com características e especificidades que não são facilmente encontráveis em outros países.

\section{Variações de formatos discursivos, influências mútuas, tendências e hábitos também são forjados nas interações culturais operadas pelo jornalismo, pela publicidade, pelo cinema, dentre outros setores.}

Alguns fatores ajudam a entender a observação anterior. A noção de cultura que orienta a produção editorial dos diários brasileiros, após a década de 1970; a redefinição do papel da crítica; a percepção e a relação de consumo que os leitores mantêm com os cadernos de cultura; a avaliação que têm (como interlocutores) dos editores, repórteres ou colaboradores de tais produtos; as condições de trabalho e as rotinas de produção editorial no jornalismo cultural; os limites e desafios de um mercado cada vez mais segmentado e excludente; a interlocução com a sociedade civil; o crescente "televisionamento" dos jornais impressos; os riscos e a força ainda presentes da oficialidade no jornalismo brasileiro; e, enfim, as principais estratégias e ações que definem os processos de pauta, tematização e agendamento no chamado "segundo caderno"... Como entender tais aspectos sem uma contextualização histórica da (trans)formação cultural do Brasil contemporâneo a partir dos produtos editoriais?

É, pois, elementar considerar a dimensão histórica do problema ou objeto de pesquisa, que tende a tipificar o jornalismo cultural. Em outros termos, a variável histórica constitui um fator indispensável para situar, cercar ou delinear uma determinada investigação na área. Sem essa perspectiva, que pode ser sintetizada em maior ou menor espaço e tempo, ficaria bem mais difícil falar em especificidades de um processo ou mesmo de um produto editorial de cultura, seja numa 
perspectiva de análise ou proposição. Não se trata de fazer um estudo histórico, mas antes situar variações que possibilitam compreender do que e como se fala. Em cultura, talvez tanto quanto em outras sub-áreas, tal variável é indispensável!

Obviamente, um estudo sobre jornalismo cultural também deve indicar a escolha de universo de amostragem, capaz de possibilitar uma representação mínima, plural ou pontual, do recorte temático. A não ser em raros casos, ficaria muito difícil sustentar uma pesquisa sem uma observação sistemática empírica de um objeto, serviço/produto, relação ou processo de produção. Não significa dizer que estudos conceituais não tenham legitimidade, mas que o diálogo teórico com a realidade social (fatores de mercado, elementos, variáveis etc) é fundamental, seja para indicar outros aspectos de um conhecimento ou mesmo para sugerir pistas possíveis capazes de reconfigurar a lógica de produção cultural.

E qual seria uma amostragem empírica defensável para uma pesquisa em jornalismo cultural? Tal questionamento só pode ser dimensionado num diálogo entre os objetivos de uma determinada investigação, o problema formulado e o objeto de pesquisa escolhido. Daí porque se diz, muito habitualmente, que não há fórmula de pesquisa em ciências sociais. No jornalismo cultural, ao que tudo indica, nem poderia ser diferente!

Na mesma lógica, a justificativa de um recorte empírico - seja temático, de suporte técnico, formato discursivo ou afim - pode ser melhor apresentada se o autor da pesquisa considerar os indicadores de mercado, de produção/ circulação e consumo, que marcam o setor estudado. E, apesar da tradição pouco organizada dominante neste País (de não manter arquivos históricos ou atuais organizados), levantamentos junto a números, variáveis e demais fatores que ilustram uma situação da área podem assegurar uma contextualização do que se fala e pretende investigar. Tiragem, circulação, estrutura produtiva, influência regional/local ou nacional, consumo, área de abrangência, produtos segmentados ou dirigidos, público potencial ou real são, por exemplo, alguns dos muitos fatores que podem ser levados em conta na caracterização contextual de um processo investigativo em jornalismo cultural.

Aqui, talvez, pode-se dar materialidade às eventuais polêmicas entre as dimensões qualitativas ou quantitativas de uma pesquisa. Afinal, como demonstrar uma relação de produção/circulação e consumo cultural sem trazer à tona aspectos quantitativos e elementos relacionais que tendem a qualificar uma de- terminada situação? A resposta pode ser indicada pelo diálogo entre as dimensões que fazem parte de uma mesma pesquisa.

\section{Interações possíveis entre diferentes olhares sobre o campo cultural}

A caracterização de um objeto de pesquisa também pode envolver uma relação ou as interações possíveis entre diferentes perspectivas sobre um mesmo produto/serviço ou processo produtivo. No campo cultural (em parte, em função das disputas simbólicas do setor) a indicação e, na medida do possível, a compreensão das relações interativas que se instituem é uma possibilidade de melhor situar metodologicamente uma investigação.

Um exemplo? Como falar em jornalismo cultural impresso cotidiano do País sem ter presente o olhar dos editores, profissionais diretamente responsáveis pelos cadernos culturais dos diários? Seja porque na perspectiva desses profissionais já estão, mais ou menos implícitas, justificativas ou explicações quanto ao modo de fazer os cadernos, bem como porque, aí, pode se tratar das orientações editoriais, critérios de seleção e noticiabilidade do que entra nas páginas culturais dos jornais brasileiros. E isso pode-se ter presente não apenas nos estudos sobre rotinas produtivas (Traquina, 2004), mas em outras perspectivas de pesquisa. A realização de entrevistas com tais atores, seja na modalidade que for mais conveniente e viável, parece ser o meio mais fácil de obter tais informações.

A interação cotidiana entre os diferentes atores não necessariamente precisa ser observada em momentos de confronto ou diálogo, mas pode se revelar nas intervenções efetuadas, de modo explícito ou implícito nas formatações de produtos, citações indiretas, críticas, influências presentes ou mesmo como eventuais fontes noticiosas.

Mas, como nem tudo o que chega numa editoria de cultura é passado ao leitor/ouvinte/telespectador, é igualmente válido considerar a perspectiva de atores que operam no campo cultural e nem sempre obtêm a pretendida expressão, visibilidade e projeção midiática. Em outros termos, o campo cultural não termina, e também não começa, na produção de mídia. Embora, nas sociedades contemporâneas, ficaria um pouco difícil ilustrar o cenário cultural sem a cotidiana ação instituinte dos produtos, espaços e periódicos da área. Naturalmente, um recorte investigativo é que poderia sugerir o que é elementar ou tangencial numa proposição de pesquisa em jornalismo cultural. A mesma variável (de ator social) pode ser indicada pela consideração à presença de grupos, ini- 
ciativas e ações empresariais que operam na área. É a necessária compreensão da presença e influência das indústrias culturais que integram o campo cultural contemporâneo.

A depender do enfoque elaborado, uma melhor caracterização do campo temático, a partir do que se produz em jornalismo cultural, não poderia ignorar as relações de consumo. Em outras palavras, o modo como os usuários se relacionam e se apropriam de tais produtos ou serviços culturais, seja considerando a noção de leitor-sujeito do consumo/leitura, ou mesmo pela expectativa e projeção de perfil que boa parte das empresas de mídia garantem manter em relação aos seus consumidores quando dão forma e materialidade aos produtos editoriais. E isso não valeria apenas para os conhecidos estudos de recepção! Uma caracterização do campo cultural pode ser melhor apresentada se indicar, mesmo que de forma breve e panorâmica, alguns fatores que marcam as relações (principais) com que o usuário tende a se nortear ao entrar em contato com os produtos editoriais de cultura.

Espaços de circulação, freqüência, giro e interação cotidiana! Embora o ambiente de redes, com mais ênfase a partir da segunda metade dos anos 1990, tenha reconfigurado algumas ações de mídia, é indispensável ter presente os espaços sociais de circulação, freqüência e consumo em que os usuários do campo cultural se deslocam. E isso não se refere apenas às instituições tradicionais de algumas poucas metrópoles nacionais. Mas de ter presente que a instituição cotidiana da cultura - que passa e é legitimada pela noticiabilidade periodística - se processa também pela existência de locais físicos de consumo, interação e diálogo entre os diversos atores sociais. Em outros termos, tanto um jornalista que atua no campo cultural como um artista que busca visibilidade para seu trabalho ou mesmo um amante das manifestações culturais contemporâneas não desconsideram a vivência cotidiana de circulação e presença nos espaços de produção e consumo simbólico da área.

E isso, ao seu modo, as cidades, bairros ou comunidades das mais diversas regiões brasileiras mantêm ou instituem pelas próprias relações de sociabilidade. Não se trata de considerar como espaço físico cultural apenas os centros de arte, salas de cinema alternativo ou ambientes universitários. Feiras livres, bares, listas de discussões/chats, cafés, esquinas de bate-papo, dentre outros locais podem se tornar referências de diálogo e ação cultural. Ao jornalista que atua ou vislumbra um estudo na área cultural, é elementar a identificação e circulação em tais espaços.
Calendário, rotinas e hábitos da circulação cultural! Outra variável do campo cultural brasileiro contemporâneo diz respeito ao calendário de lançamento e atualização periódica que cada setor mantém. Isso vale para a especificidade dos lançamentos editoriais, troca (semanal) do cartaz de cinema, teatro, lançamento musical, dentre outras referências que, guardadas as proporções, possuem lógicas próprias e diferenciadas. Um exemplo da implicação prática desta variável: a escolha de um determinado período (mês, semana, dias ou horário, dependendo do produto/serviço) pode influenciar diretamente na caracterização do estudo.

Outra tendência muito freqüente nos estudos da área é a análise de produtos culturais. Tais proposições vão desde as conhecidas "análises discursivas" (com as mais diferenciadas formulações), " de conteúdo", "semióticas", "antropológicas", dentre outras denominações e variações. Longe de centrar uma crítica em tais iniciativas, trata-se aqui de sugerir que muitos dos elementos acima indicados poderiam, na medida do possível, auxiliar na caracterização e compreensão das especificidades dos produtos ou objetos analisados. Afinal, se alguns modelos de análises de produto cultural podem dar conta das formatações discursivas, não necessariamente consideram as especificidades dos complexos processos de produção, circulação e consumo da área.

Tais estudos, que muito freqüentemente são denominados de "micro" análises, nem sempre consideram certas especificidades que tipificam as produções editoriais do campo cultural. Isso porque, para além de sua formatação aparente, os processos jornalísticos (na lógica das rotinas, que pressupõem critérios de seleção, recorte temático, escolha de fontes, em diálogo com os limites de espaço/tempo e dispositivos de negociação cotidiana) estão pautados em características próprias da área.

Aqui, as principais características do jornalismo poderiam operar como dispositivos com desdobramentos em categorias de observação, descrição e acompanhamento sistemático de uma pesquisa. Proximidade, universalidade, interesse público, atualidade, periodicidade, pluralidade, dentre outras, podem tipificar tanto o processo norteador da produção quanto a perspectiva de circulação e consumo jornalísticos.

Ao considerar estas diversas variáveis e possibilidades de recursos metodológicos de observação de produtos relacionados ao jornalismo cultural, é possível buscar referenciais de discussão e análise próprios deste setor jornalístico, motivando assim o desenvolvimento de estudos capazes de contemplar diferentes 
olhares em torno da produção/circulação/consumo da cultura pelo jornalismo e, ao mesmo tempo, contribuir para uma formação profissional mais sólida na área. Desse modo, os elementos, pistas e referências sobre as lógicas e estratégias que marcam o jornalismo cultural apresentadas neste breve texto procuram dar conta desta demanda de pesquisa e, ainda, propor uma leitura mais plural e abrangente do jornalismo cultural.

\section{Na medida em que tais}

\section{reflexões indicam pistas para}

cercar, explicar e melhor

compreender os processos de

produção jornalística no

\section{campo cultural, pode-se}

\section{simultaneamente utilizar as}

mesmas referências para

discutir estratégias de ação

\section{no ensino e formação profissional da área.}

Pode-se, assim, considerar como referência fundamental os critérios de produção editorial no jornalismo brasileiro, dentre os quais se destacam os mecanismos de seleção e agendamento; a pluralidade e factualidade das pautas; as rotinas produtivas: estrutura de produção própria, hábitos e horários de fechamento; orientações editoriais (expressas por editores e mesmo perceptíveis nos produtos) e formatação discursiva (serviço, divulgação, matéria informativa, entrevista direta etc); principais recursos de edição, como titulação, uso da imagem, legendas, abertura de texto, chamadas, dentre outros procedimentos eventualmente utilizados na produção jornalística do campo cultural.

Em outros termos, é facilmente possível desenvolver um estudo, pesquisa ou análise de produto cultural jornalístico, considerando algumas características e mecanismos de produção editorial habitualmente utilizados na área.
Isso porque os produtos e serviços do jornalismo cultural resultam de processos de produção simbólica que são cotidianamente instituídos, negociados e forjados em relações de interação que envolvem uma variedade de atores sociais, que tendem a disputar sentidos, espaço e possibilidade de expressão identitários em tais ações culturais. De forma que eventuais tentativas de isolar produtos para pesquisar e compreendê-los em suas especificidades demandam, simultaneamente, a caracterização e a indicação de algumas das variáveis e elementos que marcam o processo de produção cultural pela prática jornalística.

É claro que as mais diversas intervenções dos atores no complexo processo de produção jornalística derivam de motivações e interesses que tendem a ser justificados por modos de agir no fazer cotidiano do campo cultural, seja pela perspectiva de editores, repórteres, fontes, interlocutores, quanto de agentes culturais e, simultaneamente, dos usuários ou consumidores dos respectivos produtos/serviços.

Assim, o cruzamento de alguns desses diversos olhares e perspectivas, aliado ou paralelo às eventuais análises de um produto jornalístico-cultural, possibilita a identificação do que é aqui apresentado como uma série de variáveis lógicas que orientam e perpassam a produção jornalística da cultura brasileira.

Essas várias e diferentes perspectivas em torno de um mesmo produto possibilitariam a elaboração de um mapa da produção jornalística da cultura e, ao mesmo tempo, uma caracterização de algumas das principais estratégias editoriais na tematização, agendamento e simultânea instituição das relações que formam o campo cultural do Brasil contemporâneo.

\section{Considerações finais}

Enfim, qual seria a utilidade possível de se discutir referências metodológicas em jornalismo cultural, seja em relação à produção cotidiana do setor, quanto para a prática da formação profissional em Escolas de Comunicação (Jornalismo, em particular)? Na medida em que tais reflexões indicam pistas para cercar, explicar e melhor compreender os processos de produção jornalística no campo cultural, pode-se simultaneamente utilizar as mesmas referências para discutir estratégias de ação no ensino e formação profissional da área.

Afinal, quando se fala em considerar as características editoriais e levantar as mais diversas variáveis que instituem e marcam o processo de produção jornalística da cultura brasileira contemporânea, é razoável ponderar que tais preocupações podem servir de base para se discutir demandas de formação acadêmi- 
ca e profissional em jornalismo cultural. O efeito pragmático da contextualização social da produção jornalística teria, portanto, a real potencialidade de indicar elementos para pensar e, de certo modo, também nortear orientações para práticas pedagógicas em disciplinas, projetos e demais iniciativas didáticas em jornalismo cultural. E isso, sem muitas dificuldades, poderia servir de base para contribuir na formação profissional em jornalismo, nos mais diversos cursos superiores da área.

A operacionalidade e a crítica às referências aqui indicadas, contudo, podem ser tema e objeto de outros futuros textos. Talvez, tão ou mais pertinentes que a modesta iniciativa que você, leitor e profissional da área, acaba de ler $\square$ FAMEcos

\section{REFERÊNCIAS}

BOURDIEU, Pierre. Coisas ditas. 2.ed. São Paulo: Brasiliense, 1990.

CANCLINI, Néstor García. Diarios locales, ¿miradas globales? ¿Cómo se ocupan los medios de la información cultural? La información cultural en periódicos mexicanos. Cidade do México, 2002. Revista Etcétera. Disponível em: <http://www.etcetera.com.mx/ cancli.asp.Junho/2002>. Acesso: em 21 out. 2002.

COELHO, Marcelo. Jornalismo cultural. In: Um País aberto: reflexões sobre a Folha de S. Paulo e o jornalismo contemporâneo. São Paulo: Publifolha, 2003. p: 134-137. GADINI, Sérgio Luiz. Interesses cruzados: a produção da cultura no jornalismo brasileiro. São Paulo: Editora Paulus, 2009.

GENRO FILHO, Adelmo. O segredo da pirâmide: para uma teoria marxista do jornalismo. 2. ed. Porto Alegre: Ortiz, 1988.

LOPES, Maria Immacolata V. Pesquisa em Comunicação. São Paulo: Loyola, 1996.

MOUILLAUD, Maurice e PORTO, Sérgio Dayrell (Org.). O Jornal: da forma ao sentido. Brasília: Paralelo 15, 1997.

PIZA, Daniel. Jornalismo cultural. São Paulo: Contexto, 2003.

RIVERA, Jorge B. El periodismo cultural. Buenos Aires: Paidós, 1995.

THIOLLENT, Michel. Crítica metodológica, investigação social e enquete operária. São Paulo: Polis, 1987.
TRAQUINA, Nelson. Teorias do jornalismo: porque as notícias são como são. vol 1. Florianópolis: Editora Insular/PosJor UFSC, 2004.

TUBAU, Ivan. Teoria y pratica del periodismo cultural. Barcelona: A.T.E. Fontes, 1982.

TUCHMAN, Gaye. La producción de la noticia: estudio sobre la construcción de la realidad. Barcelona: Gustavo Gilli, 1983.

VILLA, María J. Una aproximación teórica al periodismo cultural. Revista Latina de Comunicación Social. La Laguna (Tenerife), n. 35, nov./2000. Disponível em: $<$ http://www.ull.es/publicaciones/latina/argentina2000/09villa.htm>. Acesso em 21 out. 2002.

\section{NOTAS}

* Uma versão do mesmo texto foi apresentada no Encontro Nacional de Pesquisadores do Jornalismo (SBPJor) de 2008, realizado entre os dias 19 e 21 de novembro na Universidade Metodista de São Paulo (UMESP), em São Bernardo do Campo (SP).

${ }^{1} \mathrm{O}$ presente texto resulta de uma pesquisa (do autor) sobre Jornalismo Cultural nos principais diários impressos do País. O referido estudo indicou que, para além da pouca bibliografia na área, verifica-se uma precariedade de mecanismos teórico-metodológicos capazes de contemplar as especificidades do setor, aspecto este que tem dificultado, mesmo que parcialmente, o desenvolvimento de pesquisas de graduação (e também de pós-graduação) em Jornalismo Cultural no Brasil.

${ }^{2}$ Como se vê, o conceito de Jornalismo Cultural aqui apresentado é do próprio autor. Contudo, faz referência, mesmo que indireta, a discussões e aspectos já abordados por diversos pensadores da área, entre os quais pode-se citar Iván Tubau (1982), María J. Villa (2000), Jorge Rivera (1995), Daniel Piza (2003) e Marcelo Coelho (2003).

${ }^{3}$ Essa discussão é, oportunamente, realizada por Michel Thiollent (1987, p. 33).

${ }^{4} \mathrm{O}$ referido período é importante porque registra, no Brasil, o surgimento e o sucessivo fortalecimento da produção cotidiana dos cadernos culturais pelos principais diários brasileiros. 